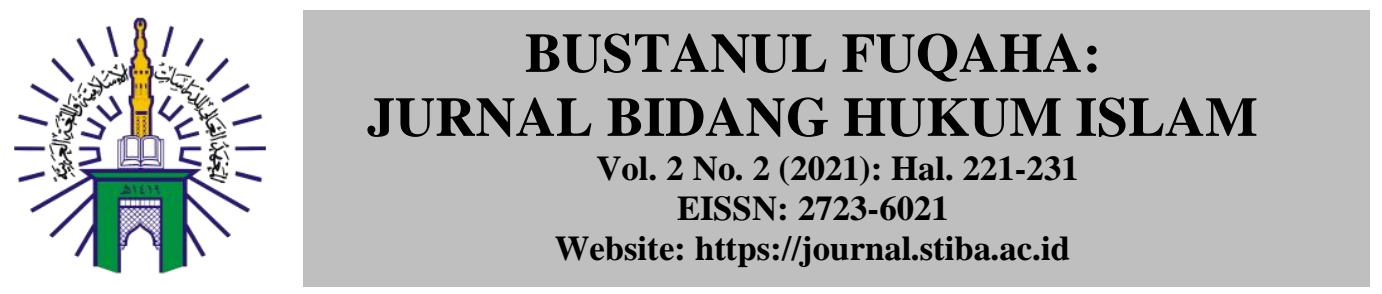

\title{
MENYENTUH MUSHAF TANPA WUDU DALAM PERSPEKTIF MAZHAB SYĀFI'Ī DAN HANBALI
}

\section{TOUCHING MUSHAF WITHOUT WUDU IN THE PERSPECTIVE OF SHĀFI'I AND HANBALI SECT}

\author{
Saifullah Bin Anshor \\ Sekolah Tinggi Ilmu Islam dan Bahasa Arab (STIBA) Makassar \\ Email: saifullah@stiba.ac.id \\ Sartini Lambajo \\ Sekolah Tinggi Ilmu Islam dan Bahasa Arab (STIBA) Makassar \\ Email: sartini@stiba.ac.id

\section{Dewi Indriani} \\ Sekolah Tinggi Ilmu Islam dan Bahasa Arab (STIBA) Makassar \\ Email: dewiindriani@stiba.ac.id

\section{Rizqa Izzati} \\ Sekolah Tinggi Ilmu Islam dan Bahasa Arab (STIBA) Makassar \\ Email: rizqa.izzati21@gmail.com
}

\begin{tabular}{|c|c|}
\hline Keywords : & ABSTRACT \\
\hline $\begin{array}{l}\text { Hadas, mushaf, Qur'an, } \\
\text { touching, wudu }\end{array}$ & $\begin{array}{l}\text { This study aimed to find out how the law of touching Mushaf of the } \\
\text { Qur'an for people who are in hadas according to the Syafi't and } \\
\text { Hanbali schools. The type of study was descriptive qualitative } \\
\text { research that focuses on retrieving data sources from library } \\
\text { research using a normative juridical approach. The results showed } \\
\text { that the sects of Syāfi't and Hanbali both viewed the prohibition of } \\
\text { touching Mushaf of the Qur'an without wudu for the person in hadas. } \\
\text { As for the law of touching or carrying a mushaf wrapping sheath } \\
\text { (which has a hanger) or a box in which there is a Mushaf of the } \\
\text { Qur'an, the sects of Syāfi't and Hanbali differ. The Syafi't sect thinks } \\
\text { it is haram because it is made for mushaf and converted to it like a } \\
\text { mushaf cover skin. The Hanbali sect argues that it is permissible not } \\
\text { to touch the mushaf because what is forbidden is touching, while } \\
\text { carrying does not mean touching. This difference arises because of } \\
\text { differences in views on the basis of qiyas in the source of the law of } \\
\text { its sect. }\end{array}$ \\
\hline \multirow{2}{*}{$\begin{array}{l}\text { Kata kunci : } \\
\text { Hadas, mushaf, Al-Qur'an, } \\
\text { menyentuh, wudu, }\end{array}$} & ABSTRAK \\
\hline & $\begin{array}{l}\text { Penelitian ini bertujuan untuk mengetahui bagaimana hukum } \\
\text { menyentuh mushaf bagi orang yang berhadas menurut mazhab } \\
\text { Syāfi' } \overline{1} \text { dan Hanbali. Jenis penelitian ini adalah penelitian kualitatif } \\
\text { deskriptif yang terfokus pada pengambilan sumber data dari buku- } \\
\text { buku perpustakaan (library research) dengan menggunakan } \\
\text { pendekatan yuridis normatif. Hasil penelitian menunjukkan bahwa } \\
\text { mazhab Syāfi' } \overline{1} \text { dan Hanbali sama-sama memandang keharaman } \\
\text { menyentuh mushaf tanpa wudu bagi orang yang berhadas. Adapun } \\
\text { terkait dengan hukum menyentuh atau membawa sarung }\end{array}$ \\
\hline
\end{tabular}




pembungkus mushaf (yang memiliki gantungan) atau kotak yang di
dalamnya terdapat mushaf Al-Qur'an, mazhab Syāfi'ī dan Hanbali
berbeda pendapat. Mazhab Syāfi'̄ berpendapat haram karena ia
dibuat untuk mushaf dan dinisbatkan kepadanya seperti kulit sampul
mushaf. Adapun mazhab Hanbali berpendapat boleh dengan syarat
tidak menyentuh mushaf karena yang dilarang adalah menyentuh,
sedangkan membawa tidak berarti menyentuh. Perbedaan ini muncul
karena adanya perbedaan pandangan terhadap dasar qiyas dalam
sumber hukum mazhabnya.

Diterima: 13 Agustus 2021; Direvisi: 16 Agustus 2021; Disetujui: 16 Agustus 2021; Tersedia online: 20 Agustus 2021

How to cite: Saifullah Bin Anshor, Sartini Lambajo, Dewi Indriani, \& Rizqa Izzati. "Menyentuh Mushaf Tanpa Wudu dalam Perspektif Mazhab Syāfi'’̄̄ dan Hanbali”, BUSTANUL FUQAHA: Jurnal Bidang Hukum Islam 2, No. 2 (2021): 221-231. doi: 10.36701/bustanul.v2i2. 375.

\section{PENDAHULUAN}

Al-Qur'an merupakan bacaan utama bagi setiap muslim yang mempunyai berbagai keistimewaan dan kelebihan dibandingkan dengan membaca bacaan yang lain. Di antara keutamaan Al-Qur'an bagi orang yang membaca dan mempelajarinya adalah menjadi syafa'at di hari kiamat, sebagaimana hadis dari Abu Umamah al-Bahili ra., dia berkata, "Saya mendengar Rasulullah saw. bersabda,

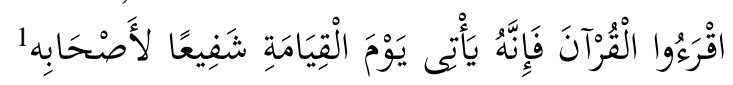

Artinya:

'Bacalah oleh kalian Al-Qur'an karena ia (Al-Qur'an) akan datang pada Hari Kiamat kelak sebagai pemberi syafa'at bagi orang-orang yang rajin membacanya'." (H.R. Muslim, no. 804)

Al-Qur'an tentunya berbeda dengan kitab para ulama atau bacaan biasa. Bagi seorang muslim yang ber-muläzamah dengan Al-Qur'an hendaknya memperhatikan adab-adab terhadap Al-Qur'an karena Al-Qur'an merupakan ayat-ayat suci kalam Rabbul 'Ālamīn. Allah swt. berfirman dalam Q.S. al-Waqi'ah/56 : 77-80,

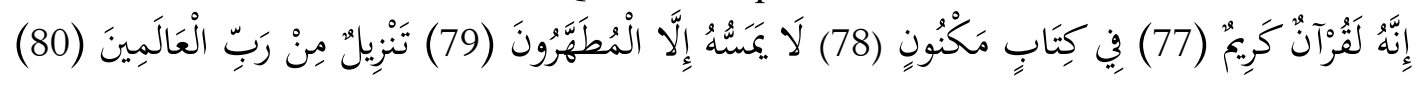

Terjemahnya:

"Dan (ini) sesungguhnya Al-Qur'an yang sangat mulia, dalam kitab yang terpelihara (Lauh Mahfüz), tidak ada yang menyentuhnya selain hamba-hamba yang disucikan. Diturunkan dari Tuhan seluruh alam."2

Ayat di atas merupakan salah satu ayat yang sering digunakan oleh para ulama dalam menerangkan permasalahan adab berinteraksi dengan Al-Qur'an yaitu bersuci. Namun demikian, dalam kehidupan sehari-hari, masyarakat Indonesia yang mayoritas bermazhab Syāfi'ī tampak tidak terlihat penerapan adab tersebut ketika berinteraksi

\footnotetext{
${ }^{1}$ Abu al-Hasan Muslim bin al-Hajjāj al-Qusyairī al-Naisābūrī, Shahīh Muslim, hadis no. 804 (Cet. I; Riyadh: Dār Ṭaybah, 2006 M/1427 H), h. 361.

${ }^{2}$ Kementrian Agama R.I., Qur'an Hafalan dan Terjemahannya, h. 537.
} 


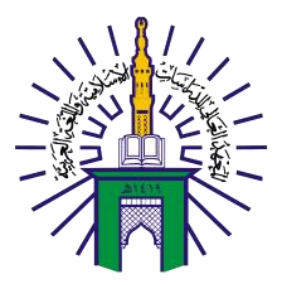

\section{BUSTANUL FUQAHA: \\ JURNAL BIDANG HUKUM ISLAM \\ Vol. 2 No. 2 (2021): Hal. 221-231 \\ EISSN: 2723-6021 \\ Website: https://journal.stiba.ac.id}

dengan Al-Qur'an, khususnya para pelajar atau anggota komunitas tilawah yang sangat sering bermulazamah dengan Al-Qur'an.

Penelitian ini bertujuan untuk mengetahui bagaimana hukum menyentuh mushaf bagi orang yang berhadas menurut mazhab Syāfi' '̄ dan Hanbali. Untuk mendapatkan jawaban dari masalah tersebut, peneliti memilih jenis penelitian kualitatif deskriptif yang terfokus pada pengambilan sumber data dari buku-buku perpustakaan (library research). Pendekatan yang digunakan dalam penelitian ini adalah pendekatan yuridis normatif.

Dari pengamatan peneliti, telah banyak penelitian terdahulu terkait dengan hukum atau adab dalam menyentuh mushaf Al-Qur'an, di antaranya;

1. Skripsi yang berjudul "Pemahaman Hadis Tentang Larangan Membaca dan Menyentuh Mushaf Al-Qur'an Saat Haid: Studi Kasus Mahasiswi Pesantren Takhassus IIQ Jakarta, yang ditulis oleh Tuti Atianti mahasiswi Fakultas Ushuluddin UIN Syarif Hidayatullah, tahun 2018. Hasil dari penelitian ini adalah bahwa tingkat pengetahuan mahasiswi IIQ terkait hadis larangan membaca dan menyentuh mushaf Al-Qur'an tidak sejalan dengan pemahamannya, artinya mereka mengetahui terdapat hadis yang melarang perempuan haid membaca dan menyentuh mushaf Al-Qur'an akan tetapi pada tingkat pemahaman hadis mereka cenderung memilih pada pendapat yang membolehkan. Terlebih di Pesantren Takhassus IIQ Jakarta yang sistem menghafal Al-Qur'annya adalah sistem kejar target hafalan, sehingga pada penelitian ini ditemukan bahwa sebagian mahasiswi tetap membaca dan menyentuh mushaf AlQur'an karna adanya keterpaksaan berupa peraturan yang diterapkan di IIQ, hal ini sejalan dengan adanya doktrin atau arahan dari pihak lembaga IIQ Jakarta. ${ }^{3}$

2. Jurnal yang berjudul "Interaksi Perempuan Haid dengan Al-Qur'an: Living AlQur'an Dengan Pendekatan Fenomelogi Agama, yang ditulis oleh Fardan Mahmudatul Imamah dan Binti Isna Aliyah, tahun 2019. Pada penelitian tersebut, data dibagi menjadi tiga bagian, yakni aspek ideational, aspek behavioral, dan aspek material. Aspek ideational menunjukkan segala yang ideal bagi santri berdasarkan transfer pengetahuan dari ustaz maupun pengasuh serta kebiasaan yang sudah ada di pondok pesantren. Aspek behavioral menunjukan keragaman cara santri mengaji meskipun dalam kondisi haid, seperti membaca dengan suara keras, tetap menyetorkan hapalan, atau sebaliknya. Aspek material, Al-Qur'an yang digunakan adalah mushaf Al-Qur'an Pojok Menara Kudus terjemah Bahasa Indonesia. ${ }^{4}$

\section{PEMBAHASAN}

\section{Pengertian Al-Qur'an}

Al-Qur'an secara bahasa merupakan kata dasar dari kata kerja "قرأ yang bermakna membaca (تلا) atau bermakna mengumpulkan (تمع). Makna pertama dari AlQur'an yaitu membaca (تلا) merupakan kata dasar dengan makna isim maf'ūl (objek) yaitu

${ }^{3}$ Tuti Atianti, "Pemahaman hadis tentang larangan membaca dan menyentuh mushaf al- qur'an saat haid: Studi kasus mahasiswi Pesantren Takhassus IIQ Jakarta”, Skripsi (Jakarta: Fak. Ushuluddin UIN Syarif Hidayatullah, 2018), h. 111

${ }^{4}$ Fardan Mahmudatul Imamah dan Binti Isna Aliyah, "Interaksi Perempuan Haid Dengan Alquran: Living Alquran Dengan Pendekatan Fenomelogi Agama. ”NUANSA (Jurnal studi Islam dan kemasyarakan) 12. No 2 (Desember 2019) DOI: http://dx.doi.org/10.29300/nuansa.v12i2.2758 
(منلو) 'yang dibaca', adapun makna kedua dari Al-Qur'an yaitu mengumpulkan (جمع) merupakan kata dasar dengan makna isim fä'il (subjek) yaitu "جامع "جarena Al-Qur'an mengumpulkan berita-berita dan hukum-hukum dari Allah. ${ }^{5}$ Adapun secara istilah syari'at, Al-Qur'an merupakan kalämullah yang diturunkan kepada Rasulullah Muhammad saw., yang dimulai dengan surat al-Fatihah dan ditutup dengan surat al-Nās. ${ }^{6}$

Al-Qur'an sudah mulai ditulis pada masa Nabi saw. sebagaimana yang tertulis dalam mushaf-mushaf yang kita dapati saat ini, akan tetapi pada masa itu belum dihimpun dalam bentuk sebuah mushaf, melainkan ditulis pada pelepah kurma, kulit kulit binatang dan semisalnya. Beberapa sahabat ada yang menghafal seluruhnya dan ada pula yang hanya menghafal sebagiannya.

Ketika Abu Bakar al-Ṣiddīq ra. menjadi khalifah dan banyak penghafal Al-Qur'an terbunuh, ia menimbang jika mereka meninggal dunia semua, niscaya akan terjadi perselisihan berkenaan dengan Al-Qur'an sesudah mereka. Oleh karenanya, Abu Bakar bermusyawarah dengan para sahabat untuk mengumpulkannya (Al-Qur'an) dalam sebuah mushaf dan mereka setuju dengannya. Abu Bakar ra. Kemudian menyuruh untuk menulis dalam sebuah mushaf dan menyimpannya di rumah Hafsah, Ummul Mukminin ra. Ketika Islam sudah tersebar pada masa pemerintahan Usman ra. ia takut terjadi perselisihan yang menyebabkan pengurangan pada sesuatu ayat dari Al-Qur'an atau terjadi penambahan di dalamnya. Usman ra. menyalin kumpulan Al-Qur'an yang ada pada Hafsah dan disetujui oleh para sahabat dalam mushaf-mushaf dan mengirimkannya ke berbagai negeri serta menyuruh melenyapkan tulisan yang bertentangan dengan itu.

Nabi saw. tidak menjadikannya dalam satu mushaf karena beliau khawatir dan bimbang akan terjadinya penambahan dan penghapusan sebagian tulisan. Kebimbangan itu terus berlangsung hingga wafatnya Nabi saw. Ketika Abu Bakar dan para sahabat lainnya merasa aman dari kebimbangan itu dan menghendaki pengumpulannya maka para sahabat ra. pun melakukannya.

Para ulama berbeda pendapat berkenaan dengan jumlah mushaf yang dikirimkan Usman. Imam Abu Amrin al-Dāni berkata bahwa sebagian besar ulama mengatakan bahwa Usman menulis empat naskah. Ia mengirim satu naskah ke Bașrah, satu ke Kufah dan satu ke Syam, sedangkan yang satu lagi disimpan. ${ }^{7}$

Abu Hatim al-Sijistāni berkata, "Usman menulis tujuh mushaf. Dia mengirimkan satu mushaf ke Mekah, satu mushaf ke Syam, satu mushaf ke Yaman, satu mushaf ke Bahrain, satu mushaf ke Bashrah, satu mushaf ke Kufah dan satu mushaf disimpan bersamanya di Madinah. ${ }^{8}$

\section{Adab-adab Membaca Al-Qur'an}

Orang yang membaca Al-Qur'an sudah sepatutnya menunjukkan keikhlasan dan menjaga adab terhadap Al-Qur'an, menghadirkan hatinya karena sedang bermunajat

\footnotetext{
${ }^{5}$ Muhammad bin Șāliḥ al-'Utsaimīn, Ușūlun fi al-Tafsīr, (Cet. 7; Riyadh: Muassasah al-Syeikh Muhammad bin Șāliḥ al-'Utsaimīn al-Khairiyah, 1441 H), h. 10.

${ }^{6}$ Muhammad bin Șālih al-‘Utsaimīn, Ușūlun fi al-Tafsīr, h. 10.

${ }^{7}$ Abu Zakariya Muhyi al-Dīn Yahya bin Syaraf al-Nawawi, al-Tibyān fì Ādāb Hamalati Al-Qur'ān (Cet. I; Beirut: Maktabah al-Muayyid, 1991 M/1412 H), h. 186-189.

${ }^{8}$ Abu Zakariya Muhyi al-Dīn Yahya bin Syaraf al-Nawawi, al-Tibyān fì Ādāb Hamalati Al-Qur'ān, h. 189.
} 


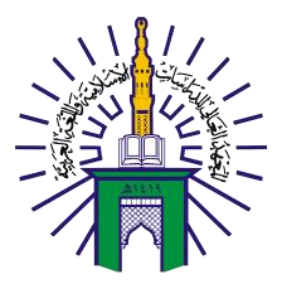

\section{BUSTANUL FUQAHA: \\ JURNAL BIDANG HUKUM ISLAM \\ Vol. 2 No. 2 (2021): Hal. 221-231 \\ EISSN: 2723-6021 \\ Website: https://journal.stiba.ac.id}

kepada Allah swt. dan membacanya seperti keadaan orang yang melihat Allah swt., jika dia tidak melihat-Nya, sesungguhnya Allah swt. melihatnya. ${ }^{9}$ Di antara adab-adab membaca Al-Qur'an adalah sebagai berikut:

1. Hendaknya membersihkan mulut dengan siwak atau lainnya sebelum membaca AlQur'an. ${ }^{10}$

2. Diutamakan membaca Al-Qur'an dalam keadaan suci. ${ }^{11}$

3. Disunahkan membaca Al-Qur'an di tempat yang bersih dan terpilih. Sejumlah ulama menganjurkan membaca Al-Qur'an di masjid karena ia meliputi kebersihan dan kemuliaan tempat serta menghasilkan keutamaan lain yaitu $i^{\prime}$ 'tikaf. ${ }^{12}$

4. Diutamakan membaca Al-Qur'an (di luar shalat) dengan menghadap kiblat. ${ }^{13}$

5. Jika hendak mulai membaca Al-Qur'an, memohon perlindungan dengan mengucapkan,

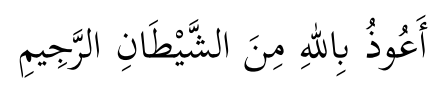

Artinya:

"Aku Berlindung kepada Allah dari syaitan yang terkutuk".

Sebagian ulama salaf berkata $t a{ }^{\prime} a w w u d z$ itu sepatutnya dibaca sebelum membaca AlQur'an. Allah swt. berfirman dalam Q.S. al-Nahl/16: $98,{ }^{14}$

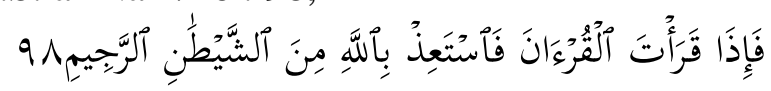

Terjemahnya:

"Maka apabila engkau (Muhammad) hendak membaca Al-Qur'an, mohonlah perlindungan kepada Allah dari setan yang terkutuk." 15

6. Hendaklah orang yang membaca Al-Qur'an selalu membaca basmalah pada awal setiap surat selain surah Bara'ah. ${ }^{16}$

7. Jika mulai membaca, hendaklah bersikap khusyuk dan merenungkan maknanya ketika membaca. ${ }^{17}$

Allah swt. berfirman dalam Q.S. Shaad/38: 29,

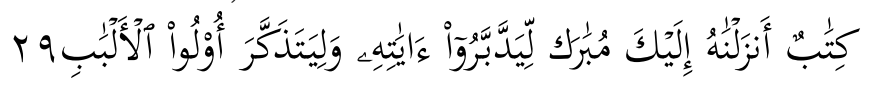

${ }^{9}$ Abu Zakariya Muhyi al-Dīn Yahya bin Syaraf al-Nawawi, al-Tibyān fì Ādāb Hamalati AlQur'ān, h. 69.

${ }^{10}$ Abu Zakariya Muhyi al-Dīn Yahya bin Syaraf al-Nawawi, al-Tibyān fì Ādāb Hamalati AlQur'ān, h. 69.

${ }^{11}$ Abu Zakariya Muhyi al-Dīn Yahya bin Syaraf al-Nawawi, al-Tibyān fì Ādāb Hamalati AlQur'ān, h. 70.

${ }^{12}$ Abu Zakariya Muhyi al-Dīn Yahya bin Syaraf al-Nawawi, al-Tibyān fì Ādāb Hamalati AlQur'ān, h. 74.

${ }^{13} \mathrm{Abu}$ Zakariya Muhyi al-Dīn Yahya bin Syaraf al-Nawawi, al-Tỉbyān fì Ādāb Hamalati AlQur'ān, h. 76.

${ }^{14}$ Abu Zakariya Muhyi al-Dīn Yahya bin Syaraf al-Nawawi, al-Tibyān fì Ādāb Hamalati AlQur'ān, h. 77-78.

${ }^{15}$ Kementrian Agama R.I., Qur'an Hafalan dan Terjemahannya, h. 278. Qur'ān, h. 80.

${ }^{16} \mathrm{Abu}$ Zakariya Muhyi al-Dīn Yahya bin Syaraf al-Nawawi, al-Tibyān fì Ādāb Hamalati Al-

${ }^{17}$ Abu Zakariya Muhyi al-Dīn Yahya bin Syaraf al-Nawawi, al-Tibyān fì Ādāb Hamalati AlQur'ān, h. 81. 
Terjemahnya:

“Kitab (Al-Qur'an) yang Kami turunkan kepadamu penuh berkah agar mereka menghayati ayat-ayatnya dan agar orang-orang yang berakal sehat mendapat pelajaran." 18

8. Diutamakan jika melalui ayat yang mengandung rahmat agar memintanya kepada Allah swt. dan apabila melalui ayat yang mengandung siksaan agar memohon perlindungan kepada Allah swt. dari kejahatan dan siksaan. ${ }^{19}$

9. Hal yang perlu diperhatikan dan amat ditekankan adalah memuliakan Al-Qur'an dari hal-hal yang terkadang diabaikan oleh sebagian orang yang lalai ketika membaca bersama-sama, di antaranya menghindari tertawa, berbuat bising dan bercakap-cakap di tengah pembacaan, kecuali perkataan yang perlu diucapkan. ${ }^{20}$ Allah swt. berfirman dalam Q.S. al-A'raf /7 : 204,

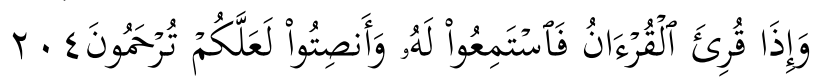

Terjemahnysa:

"Dan apabila dibacakan Al-Qur'an, maka dengarkanlah baik-baik dan perhatikanlah dengan tenang agar kamu mendapat rahmat." 21

10. Membaca Al-Qur'an dari mushaf lebih utama daripada membacanya dengan hafalan karena memandang dalam mushaf adalah ibadah yang diperintahkan. ${ }^{22}$

11. Sunah memperindah suara pada waktu membaca Al-Qur'an. Para ulama salaf dan khalaf dari kalangan sahabat, tabiin, para ulama Anshar (Baghdad, Bashrah dan Madinah) serta para imam kaum muslimin sependapat dengan sunahnya memperindah suara ketika membaca Al-Qur'an. ${ }^{23}$

12. Apabila membaca surat, kemudian menguap, hendaknya menghentikan bacaanya hingga sempurna keluarnya, kemudian kembali membaca. ${ }^{24}$ Diriwayatkan dari Abu Said al-Khudri ra., ia berkata bahwa Rasulullah saw. bersabda:

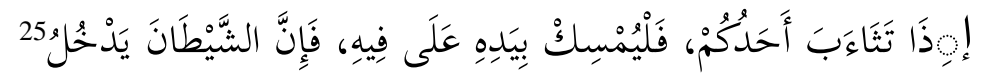

Artinya:

"Jika seseorang dari kamu menguap, hendaklah dia menutup mulutnya dengan tangannya, karena syaitan akan masuk."

\footnotetext{
${ }^{18}$ Kementrian Agama R.I., Qur'an Hafalan dan Terjemahannya, h. 455.

${ }^{19}$ Abu Zakariya Muhyi al-Dīn Yahya bin Syaraf al-Nawawi, al-Tibyān fì Ādāb Hamalati AlQur'ān, h. 90.

${ }^{20}$ Abu Zakariya Muhyi al-Dīn Yahya bin Syaraf al-Nawawi, al-Tibyān fì Ādāb Hamalati AlQur'ān, h. 91.

${ }^{21}$ Kementrian Agama R.I., Qur'an Hafalan dan Terjemahannya, h. 176.

${ }^{22}$ Abu Zakariya Muhyi al-Dīn Yahya bin Syaraf al-Nawawi, al-Tibyān fì Ādāb Hamalati AlQur'ān, h. 98.

${ }^{23}$ Abu Zakariya Muhyi al-Dīn Yahya bin Syaraf al-Nawawi, al-Tibyān fì Ādāb Hamalati AlQur'ān, h. 109.

${ }^{24}$ Abu Zakariya Muhyi al-Dīn Yahya bin Syaraf al-Nawawi, al-Tibyān fì Ādāb Hamalati AlQur'ān, h. 118.

${ }^{25}$ Abu al-Hasan Muslim bin al-Hajjāj al-Qusyairī al-Naisābūrī, Shahīh Muslim, Jilid 4, hadis no. 57, h. 2293.
} 


\section{Hukum Menyentuh Mushaf Tanpa Wudu Menurut Mazhab Syāfi’’̄}

Abu Isḥāq al-Syirāzī berkata dalam kitabnya, al-Muhażab fì Fiqhi al-Imām alSyāfi ' $\bar{l}$, bahwa orang yang berhadas diharamkan baginya menyentuh mushaf. ${ }^{26}$ Beliau berdalil dengan firman Allah Q.S. al-Wāqi'ah/56: 79,

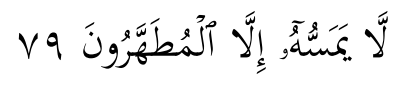

Terjemahnya:

"Tidak ada yang menyentuhnya selain hamba-hamba yang disucikan."27

Sisi pendalilan dari ayat ini yaitu Allah swt. mengabarkan bahwa Al-Qur'an alKarìm tidak disentuh kecuali oleh orang-orang yang suci sebagai bentuk pemulian dan pengagungan terhadapnya. Ayat tersebut datang dalam konteks pembatasan (al-hașr), dimana hanya dibolehkan bagi al-muțahharūn, yaitu yang suci dari hadas dan najis dari kalangan anak Adam. Ayat tersebut meski dalam bentuk kabar, akan tetapi ia juga membawa makna pelarangan sebagaimana firman Allah di Q.S. al-Baqarah/2 : 233,

Terjemahnya:

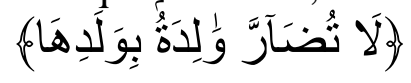

"Janganlah seorang ibu menderita karena anaknya.",28

Selain dalil dari Al-Qur'an, Imam al-Syirāzī juga berdalil dengan hadis yang diriwatkan oleh Ḥakīm bin Ḥizām ra. bahwa Rasulullah saw. Bersabda,

$$
29
$$

Artinya:

"Janganlah engkau menyentuh Al-Qur'an kecuali dalam keadaan suci."

Imam Nawawi dalam kitabnya, al-Majmū’ Syarh al-Muhażżab, menjelaskan secara detail terkait larangan menyentuh mushaf dalam keadaan berhadas dalam pandangan mazhab Syāfi' '̄ sebagai berikut:

1. Para ulama Syāfi'iyyah berpendapat bahwa orang yang berhadas haram hukumnya menyentuh mushaf, baik itu tulisannya, spasi antara tulisan, pinggirannya, atau sampulnya sekalipun. ${ }^{30}$

2. Terdapat dua pendapat terkait hukum menyentuh sarung pembungkus (yang memiliki gantungan), atau kotak yang di dalamnya terdapat mushaf Al-Qur'an, dan pendapat yang paling benar di antara keduanya adalah haram hukumnya; karena ia dibuat untuk mushaf dan dinisbatkan kepadanya seperti kulit mushaf. ${ }^{31}$

3. Hukum membolak-balikkan lembaran mushaf menggunakan tongkat, lidi atau semacamnya, terdapat dua pendapat yang masyhur di kitab para ulama Khurasan terkait masalah tersebut. Pendapat yang paling tepat di antara keduanya adalah boleh;

${ }^{26} \mathrm{Abu}$ Isḥāq Ibrahim bin 'Ali bin Yusuf al-Syirāzī, al-Muhażab fì Fiqhi al-Imām al-Syāfi ’’, Jilid 1 (Cet. I; Damaskus: Dār al-Qalam, 1992 M/ 1412 H), h. 103.

${ }^{27}$ Kementrian Agama R.I., Qur'an Hafalan dan Terjemahannya, h. 537.

${ }^{28}$ Kementrian Agama R.I., Qur'an Hafalan dan Terjemahannya, h. 37.

${ }^{29}$ Abu al-Qāsim Sulaiman bin Ahmad al-Thabrānī, al-Mu'jam al-Kabīr, Jilid 3, hadis no. 3135 (Cet. 2; Kairo: Maktabah Ibnu Taimiyah, t.th.), h. 205.

${ }^{30}$ Abu Zakariya Muhyi al-Dīn Yahya bin Syaraf al-Nawawi, al-Majmū' Syarh al-Muhażab, h. 79.

${ }^{31}$ Abu Zakariya Muhyi al-Dīn Yahya bin Syaraf al-Nawawi, al-Majmū’ Syarh al-Muhażab, h. 80. 
karena ia tidak dikategorikan menyentuh mushaf secara langsung ataupun membawanya. ${ }^{32}$

4. Adapun apabila ia melipat lengan bajunya dan diletakkan di atas telapak tangannya, kemudian ia gunakan untuk membolak-balikkan lembaran mushaf, maka hukumnya adalah haram, sebagaimana pendapat jumhur ulama Syafi'iyyah. Mereka membedakan antara penggunaan tongkat kayu dengan lengan baju karena lengan baju itu melekat pada orang tersebut dan dihukumi sebagai bagian dari dirinya, sebagaimana ia juga dilarang sujud di atasnya karena yang sebenarnya digunakan untuk membolakbalikkan adalah tangan bukan lengan baju. ${ }^{33}$

5. Terdapat dua pendapat terkait membawa mushaf bersamaan dengan benda lainnya, dan pendapat yang lebih tepat adalah tidak diharamkan; karena ia tidak meniatkan membawa mushaf secara khusus. ${ }^{34}$

6. Anak kecil yang belum mumayyiz atau belum bisa membedakan baik dan buruk, walinya tidak boleh memberikan kepadanya mushaf agar ia tidak merendahkannya. Adapun yang sudah mumayyiz atau dapat membedakan antara baik dan buruk, maka para wali dan guru tidak harus membebankan kepada mereka bersuci setiap ingin membawa mushaf atau menyentuhnya; karena itu sulit bagi mereka. ${ }^{35}$

7. Apabila seseorang yang berhadas lalu ia bertayamum karena tidak mendapati air dengan tayamum yang benar, maka boleh baginya menyentuh mushaf, dan juga termasuk yang hadasnya belum hilang seperti orang yang berwudu dalam keadaan berhadas yang berkelanjutan seperti keluarnya darah istihậdah, maka boleh pula baginya menyentuh dan membawa mushaf. Adapun terkait orang yang tidak menemukan air atau tanah untuk bersuci, maka ia boleh langsung salat dalam keadaan tersebut karena darurat, dan tidak boleh baginya menyentuh mushaf serta membawanya karena tidak adanya kondisi darurat untuk melakukannya. ${ }^{36}$

8. Jika seorang yang berhadas khawatir terhadap suatu mushaf yang akan basah tenggelam, terbakar, terkena najis, atau dipegang oleh orang kafir, dan tidak memungkinkan baginya bersuci maka boleh ia mengambil mushaf tersebut meski dalam keaadan berhadas karena kondisi darurat. ${ }^{37}$

Demikian beberapa pandangan mazhab Syāfi' 'ī yang dijelaskan oleh Imam Nawawi al-Syāfi'ī terkait hukum menyentuh mushaf tanpa wudu atau seorang yang berhadas.

\footnotetext{
${ }^{32}$ Abu Zakariya Muhyi al-Dīn Yahya bin Syaraf al-Nawawi, al-Majmū' Syarh al-Muhażab, h. 80.

${ }^{33}$ Abu Zakariya Muhyi al-Dīn Yahya bin Syaraf al-Nawawi, al-Majmū' Syarh al-Muhażab, h. 80.

${ }^{34}$ Abu Zakariya Muhyi al-Dīn Yahya bin Syaraf al-Nawawi, al-Majmū' Syarh al-Muhażab, h. 80.

${ }^{35}$ Abu Zakariya Muhyi al-Dīn Yahya bin Syaraf al-Nawawi, al-Majmū' Syarh al-Muhażab. h. 81-

${ }^{36}$ Abu Zakariya Muhyi al-Dīn Yahya bin Syaraf al-Nawawi, al-Majmū' Syarh al-Muhażab, h. 84.

${ }^{37}$ Abu Zakariya Muhyi al-Dīn Yahya bin Syaraf al-Nawawi, Rauḍh al-Tâlibìn wa 'Umdah alMuftiyyin, Jilid 1 (Cet. III; Beirut: al-Maktab al-Islāmī, 1991 M/1412 H), h. 81.
} 82. 


\section{Hukum Menyentuh Mushaf Tanpa Wudu Menurut Mazhab Hanbali}

Ibnu Qudāmah al-Maqdisī al-Hanbalī berkata dalam kitabnya, al-Muqni' fì Fiqhi al-Imām Ahmad bin Hanbal al-Syaibān̄̄, bahwa barangsiapa yang berhadas maka diharamkan baginya salat, tawaf, dan menyentuh mushaf. ${ }^{38}$

Pendapat tersebut berdalilkan firman Allah dalam Q.S. al-Wāqi'ah/56: 79,

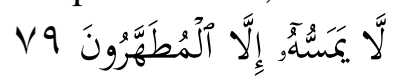

Terjemahnya:

"Tidak ada yang menyentuhnya selain hamba-hamba yang disucikan." 9

Maksudnya yakni tidak ada yang menyentuh Al-Qur'an, dimana ayat ini datang dengan konteks berita namun mengandung makna pelarangan. ${ }^{40}$

Manșūr bin Yunus al-Buhūtī al-Hanbalī menjelaskan bahwa diharamkan bagi orang yang berhadas menyentuh mushaf atau sebagiannya, termasuk kulit sampulnya, atau pinggirannya, dengan mengunakan tangan atau bagian tubuh lainnya tanpa pembatas. Tidak terlarang untuk membawanya mengunakan sesuatu yang menggantungnya atau di dalam sebuah kantong, atau di dalam lengan baju, dengan tetap tidak menyentuhnya. Tidak terlarang membolak-balikkan lembaran mushaf mengunakan lengan baju atau tongkat, begitupula tidak terlarang bagi anak kecil. ${ }^{41}$

Beliau menjelaskan lebih lanjut beberapa masalah terkait hukum menyentuh mushaf bagi orang yang berhadas menurut pandangan mazhab Hanbali melalui karyanya yang lain yaitu kitab Daqāiqu Ūlì al-Nuha lisyarḥi al-Muntahā sebagai berikut:

1. Larangan menyentuh mushaf bagi orang yang berhadas juga mencakup kulit sampulnya, dan catatan-catatan pinggirnya, serta bagian kertas yang tidak ada tulisannya; karena semua itu menyatu dalam sebuah mushaf dan dijual bersamaan. ${ }^{42}$

2. Larangan menyentuh mushaf ini berlaku baik menggunakan tangan atau bagian tubuh yang lain seperti dada; karena segala sesuatu yang bertemu (terkena) benda lainnya dikatakan bahwa ia telah menyentuhnya. ${ }^{43}$

3. Menyentuh mushaf bagi orang yang berhadas diharamkan jika tidak ada lapisan penghalang, adapun jika menggunakan penghalang maka tidak diharamkan; karena jika menggunakannya maka yang disentuh adalah penghalangnya bukan mushaf secara langsung.

4. Tidak diharamkan bagi orang yang berhadas membawa mushaf dengan sesuatu yang menggantungnya, atau di dalam kantong, dan di lengan baju, dengan syarat tidak

\footnotetext{
${ }^{38} \mathrm{Ibnu}$ Qudāmah al-Maqdisī, al-Muqni' fì Fiqhi al-Imām Ahmad bin Hanbal al-Syaibān̄̄ (Cet. I; Jeddah: Maktabah al-Sawādī, 2000 M/1421 H), h. 31.

${ }^{39}$ Kementrian Agama R.I., Qur'an Hafalan dan Terjemahannya, h. 537.

${ }^{40}$ Ibrahim bin Muhammad bin Abdullah bin Muhammad bin Muflih, al-Mubdi' fi Syarh al-Muqni', Jilid 1 (Cet. I; Beirut: Dār al-Kutub al-'Ilmiyyah, 1997 M/1418 H), h. 147.

${ }^{41}$ Manșūr bin Yunus al-Buhūṭ̣̂ al-Hanbalī, Al-Raud al-Murbi' Syarh Zād al-Mustaqni', h. 39.

${ }^{42}$ Manșūr bin Yunus al-Buhūṭī al-Ḥanbalī, Daqāiqu Ūlì al-Nuha lisyarḥi al-Muntahā, Jilid 1, h.

77.

${ }^{43}$ Manșūr bin Yunus al-Buhūṭī al-Ḥanbalī, Daqāiqu Ūlī al-Nuha lisyarhi al-Muntahā, Jilid 1, h. 
menyentuhnya, seperti membawanya di atas kendaraan; karena yang dilarang adalah menyentuh, sedangkan membawa tidak berarti menyentuh. ${ }^{44}$

5. Tidak diharamkan bagi seorang yang berhadas menyentuh mushaf menggunakan lengan bajunya, atau dengan tongkat seperti lidi dan sebagainya; dengan alasan seperti yang telah dijelaskan sebelumnya (poin ke-3). ${ }^{45}$

'Alī bin Sulaiman al-Mardāwī al-Hanbalī mengatakan bahwa orang yang berhadas dibolehkan secara mutlak dalam mazhab Hanbali menyentuh mushaf setelah bersuci dengan cara bertayamum karena tidak mendapati air. ${ }^{46}$

\section{KESIMPULAN}

Berdasarkan hasil analisis dan pembahasan di atas, penelitian menyimpulkan bahwa mazhab Syāfi' '̄ dan Hanbali sepakat bahwa menyentuh mushaf bagi orang yang berhadas mencakup tulisan ayat, spasi antarayat, kulit sampul, dan catatan-catatan pinggirnya, serta bagian kertas yang tidak ada tulisannya, adalah dilarang, baik itu menggunakan tangan atau bagian tubuh yang lain seperti dada; karena segala sesuatu yang bertemu (terkena) benda lainnya disebut menyentuh, kecuali pada kondisi darurat, seperti jika seorang yang berhadas khawatir terhadap suatu mushaf yang akan basah tenggelam, terbakar, terkena najis, atau dipegang oleh orang kafir, dan tidak memungkin baginya bersuci. Mazhab Syāfi'ī dan Hanbali berbeda pendapat terkait hukum menyentuh atau membawa sarung pembungkus mushaf (yang memiliki gantungan), atau kotak yang di dalamnya terdapat mushaf Al-Qur'an. Mazhab Syāfi' '̄ berpendapat haram hukumnya; karena ia dibuat untuk mushaf dan dinisbatkan kepadanya seperti kulit sampul mushaf. Adapun mazhab Hanbali berpendapat boleh hukumnya dengan syarat tidak menyentuh mushaf; karena yang dilarang adalah menyentuh, sedangkan membawa tidak berarti menyentuh.

\section{DAFTAR PUSTAKA}

Abu Isḥāq Ibrahim bin 'Ali bin Yusuf al-Syirāzī, al-Muhażab fì Fiqhi al-Imām al-Syāfi '̄̄. Jilid. 1. Cet. I; Damaskus: Dār al-Qalam, 103.

Al-'Utsaimīn, Muhammad bin Șāliḥ. Ușūlun fi al-Tafsīr. Cet. 7; Riyadh: Muassasah alSyeikh Muhammad bin Șālih al-'Utsaimīn al-Khairiyah, $1441 \mathrm{H}$.

Al-Ḥanbalī, 'Alī bin Sulaiman al-Mardāwī. Al-Inșāf fì Ma'rifah al-Rājịh min al-Khilāf, Jilid 1. Cet. II; Beirut: Dār Ihyē̄' al-Turās̀ al-'Arabī, t.th.

Al-Ḥanbalī, Manșūr bin Yunus al-Buhūṭ̂i. Al-Rauḍ al-Murbi' Syarh Zād al- Mustaqni'. t. Cet.; Riyadh: Dār al-Muayyid, t.th.

Al-Maqdis̄i, Ibnu Qudāmah. Al-Muqni' fì Fiqhi al-Imām Ahmad bin Hanbal al-Syaibānī. Cet. I; Jeddah: Maktabah al-Sawādī, 2000.

\footnotetext{
77.

${ }^{45}$ Manșūr bin Yunus al-Buhūṭī al-Ḥanbalī, Daqāiqu Ūlī al-Nuha lisyarḥi al-Muntahā, Jilid 1, h.

77.

46، Alī bin Sulaiman al-Mardāwī al-Hanbalī, al-Inșāf fì Ma'rifah al-Rājị̣ min al-Khilāf, Jilid 1
}

${ }^{44}$ Manșūr bin Yunus al-Buhūṭ̄ al-Ḥanbalī, Daqāiqu Ūlī al-Nuha lisyarḥi al-Muntahā, Jilid 1, h. (Cet. II; Beirut: Dār Iḥyā’ al-Turāì al-‘Arabī, t.th), h. 226. 


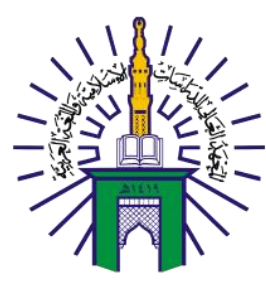

\section{BUSTANUL FUQAHA: \\ JURNAL BIDANG HUKUM ISLAM \\ Vol. 2 No. 2 (2021): Hal. 221-231 \\ EISSN: 2723-6021 \\ Website: https://journal.stiba.ac.id}

Al-Naisābūrī, Abu al-Hasan Muslim bin al-Hajjāj al-Qusyairī. Shahīh Muslim. Cet. I; Riyadh: Dār Ṭaybah, 2006.

Al-Nawawi, Abu Zakariya Muhyi al-Dīn Yahya bin Syaraf. Al-Tibyān fĩ Ādāb Hamalati Alqurān. Cet. I; Beirut: Maktabah al-Muayyid, 1991.

Al-Nawawi, Abu Zakariya Muhyi al-Dīn Yahya bin Syaraf. Rauḍh al-Tālibìn wa 'Umdah al-Muftiyyin, Jilid 1. Cet. III; Beirut: al-Maktab al-Islāmī, 1991.

Al-Sabīl, Umar bin Muhammad. Hukmu al-Tahārah li Massi Al-Qur'an al-Karīm. Cet. I; Riyadh: Dār al-Faḍilah, 2003.

Al-Thabrānī, Abu al-Qāsim Sulaiman bin Ahmad, al-Mu'jam al-Kabīr. Jilid. 3. hadis no. 3135. Cet. 2; Kairo: Maktabah Ibnu Taimiyah, 205.

Fardan Mahmudatul Imamah dan Binti Isna Aliyah, "Interaksi Perempuan Haid Dengan Al-Qur'an: Living Al-Qur'an Dengan Pendekatan Fenomelogi Agama. 'NUANSA (Jurnal studi Islam dan kemasyarakan) 12. No 2 (Desember 2019) DOI: http://dx.doi.org/10.29300/nuansa.v12i2.2758

Kementrian Agama R.I. Qur'an Hafalan dan Terjemahannya. Cet. I; Jakarta: almahira, 2015.

Muflih, Ibrahim bin Muhammad bin Abdullah bin Muhammad bin. Al-Mubdi' fi Syarh al-Muqni', Jilid 1. Cet. I; Beirut: Dār al-Kutub al-'Ilmiyyah, 1997.

Tuti Atianti, "Pemahaman hadis tentang larangan membaca dan menyentuh mushaf AlQur'an saat haid: Studi kasus mahasiswi Pesantren Takhassus IIQ Jakarta”, Skripsi (Jakarta: Fak. Ushuluddin UIN Syarif Hidayatullah, 2018. 